\title{
Análisis espacial de los accidentes de tráfico en Bogotá D.C. Fundamentos de investigación
}

Spatial analysis of traffic accidents in Bogota D. C. Principles of research

Flor Ángela Cerquera Escobar ${ }^{1}$

\section{Resumen}

En el documento se presenta una síntesis del análisis espacial de accidentes de tráfico en el área urbana de la ciudad de Bogotá D. C., y se definen los fundamentos de este análisis, a fin de orientarlo con el aporte de nuevos elementos y factores que determinen variables espaciotemporales, que sustenten la definición de patrones territoriales de ocurrencia en el área urbana de Bogotá, los que serán la base para efectuar programaciones futuras de intervenciones orientadas a prevenir y disminuir los niveles de accidentalidad, así como a mejorar los índices de seguridad vial y movilidad en la capital.

Palabras clave: accidente de tráfico, análisis espacial, patrones territoriales, elipse de desviación estándar, densidad y concentración de accidentes.

\begin{abstract}
This paper summarizes the spatial analysis of traffic accidents in the urban area of Bogota D. C., and the principles of this analysis are defined in order to guide it with the contribution of new elements and factors that determine spatiotemporal variables, that support the definition of territorial patterns of occurrence in the urban area of Bogota, which will be the basis for making future programming of interventions to prevent and reduce accident levels, as well as to improve the rates of road safety and mobility in the capital.
\end{abstract}

1 Magister en Ingeniería de Tránsito y Transporte. Docente, Universidad Pedagógica y Tecnológica de Colombia. Colombia. faceitv@uptc.edu.co 
Keywords: traffic accident, spatial analysis, regional patterns, standard deviation ellipse, density and concentration of accidents. 


\section{Introducción}

El problema de la accidentalidad vial en Colombia se concentra predominantemente en el espacio urbano, pues el 85 $\%$ de los accidentes de tránsito ocurre en áreas urbanas y el $15 \%$ restante, en áreas rurales; un poco más del $60 \%$ de los eventos sucede en las tres principales ciudades (Bogotá, Medellín y Cali), cerca del $30 \%$ en áreas urbanas de tamaño medio y pequeño, y el $10 \%$ sobre la red vial nacional (Ministerio de Transporte, 2010).

Investigar a Bogotá, en la problemática de accidentalidad, significa encontrar la mayor parte de las variables que causan - directa o indirectamente- los accidentes de tránsito que ocurren en esta ciudad, tipo metrópolis latinoamericana. En el análisis a los datos suministrados por la Secretaría Distrital de Movilidad (SDM, 2011), la capital de la república para el año 2010, concentró el $20.2 \%$ de los accidentes de tránsito, el $35.4 \%$ de los heridos y el $9.4 \%$ de las muertes del total nacional; concentración de gran relevancia, si se tiene en cuenta que en los últimos años gran parte de los recursos del sector de movilidad, se han dirigido a implementar programas y campañas de seguridad vial para contrarrestar el problema, aunque sin lograr resultados significativos en la disminución en el número de accidentes, de muertos y heridos, por cuanto desde el año 2005 los accidentes vienen ocurriendo constantemente (Cerquera \& Chías). De ahí la importancia de llevar a cabo investigaciones que profundicen en la determinación de las áreas o espacios donde se concentre el fenómeno, para orientarse con mayor certeza a disminuir los índices, identificando, cuantificando y conociendo la inseguridad vial mediante mapas en que se describan patrones de distribución y de comportamiento, que serán guías para fijar los programas de prevención y operación.

Un análisis espacial de los datos de accidentes significa que estos datos son espacialmente localizables. Los accidentes de tráfico ocurren en tiempo y espacio $y$, por lo tanto, todos los accidentes tienen una ubicación geográfica exacta que se identifica como un punto en el mapa; por ende, el análisis por realizar puede ser de un punto o un grupo de puntos que conforma una aglomeración, donde se observa la localización de eventos con un patrón de comportamiento particular u homogéneo que posee similares características de ocurrencia.

En Colombia, muy poco o nada se ha efectuado investigación geográfica en accidentes de tráfico, en donde se desarrolle análisis espaciotemporal (Cerquera \& Chías, 2010), que determine la ubicación en mapas de la distribución de los distintos tipos de accidentes y su asociación con variables de tipo socioeconómico y ambiental, para luego ser identificadas como riesgosas. Esto señala que aún no ha sido mostrada la utilidad del análisis geográfico a la hora de establecer las variables asociadas que inciden en la ocurrencia de lesiones y muertes por accidentes de tráfico.

Por eso, para la investigación, tiene un carácter vital establecer los fundamentos para el análisis espacial, por cuanto orienta y apoya la definición de las variables espaciotemporales que inciden en los eventos que vienen sucediendo en 
la ciudad de Bogotá. La determinación de variables se encamina a aportar nuevos elementos que ayudan a definir patrones territoriales en el área urbana de Bogotá, para sustentar programaciones futuras de intervenciones orientadas a reducir los índices de accidentes y mejorar la salud y bienestar de la población.

El artículo presenta una síntesis de la investigación y consta de dos partes: una parte sobre los fundamentos principales para el análisis espacial de accidentes de tráfico, y otra que muestra varios de los análisis de estos fundamentos contextualizados en el área de estudio de Bogotá D. C., en la problemática existente, delimitando variables y factores que inciden en la ocurrencia de los eventos.

\section{El análisis espacial en accidenta- lidad de tráfico}

Comprender la distribución espacial de los datos de los fenómenos que ocurren en el espacio constituye hoy un gran reto para el esclarecimiento de cuestiones centrales en diversas temáticas, como en el caso de los accidentes de tráfico. Buzai y Baxendale (2006) ano$\tan$ al respecto:

Cuando se le enfoca desde un punto de vista temático, el Análisis Espacial constituye una serie de técnicas estadísticas y matemáticas aplicada al estudio de los datos distribuidos sobre el espacio geográfico. Cuando se le enfoca desde el punto de vista de la tecnología de los Sistemas de Información Geográfica, el Análisis
Espacial se considera su núcleo ya que es el que posibilita trabajar con las relaciones espaciales de las entidades contenidas en cada capa temática de la base de datos geográfica.

O’Sullivan y Unwin (2003) presentan el análisis espacial en cuatro enfoques: manipulación de datos espaciales, análisis de datos espaciales de forma descriptiva y exploratoria, aplicación de la estadística espacial y modelado espacial para predecir eventos espaciales. $\mathrm{Al}$ análisis de la información geográfica le concierne la investigación de los patrones que resultan de los procesos que pueden estar operando en el espacio. Bailey y Gattrel (1995) señalan: "En términos amplios uno puede definir el análisis espacial como el estudio cuantitativo de fenómenos que están localizados en el espacio".

Legendre y Fortin (citados por Maestre et al, 2008) sostienen que "bajo el nombre genérico de análisis espacial se engloba a un conjunto de técnicas encaminadas a analizar cuantitativamente datos espacialmente explícitos" o "datos que contienen información sobre su localización en el espacio".

En síntesis, el análisis espacial se utiliza para la identificación, descripción, explicación y divulgación de los procesos que están operando en el espacio, o de los patrones espaciales, con el objeto de agregar valor a los datos contenidos en una geobase de datos, para la construcción de modelos espaciales y para la estimación de valores con sus errores de estimación (geoestadística). 
Ubicándonos en el contexto de los accidentes de tráfico, hacer el análisis espacial a unos datos significa que estos datos son espacialmente localizables. Los accidentes de tráfico ocurren en tiempo y espacio, por lo tanto, todos los accidentes tienen una ubicación geográfica exacta que se identifica como un punto. La contribución del análisis espacial permite identificar de manera precisa el patrón de concentración-dispersión, insumo fundamental en la determinación de modelos de evaluación con base en evidencia científica, con objetivos fundamentalmente preventivos en la toma de decisiones. Los resultados de una investigación espacial de eventos aportan nuevos elementos que fortalecen las bases de la indagación del fenómeno.

Así mismo, el análisis espacial permite reconocer y evaluar sitios, áreas y corredores inseguros de alto riesgo, la frecuencia de ocurrencias según la clase del accidente $^{2}$, realizar procesos de georreferenciación, establecer patrones tipo que lleven a la determinación de indicadores de accidentalidad, según densidad de población y de red vial, además de estudiar el movimiento de los elementos que intervienen e interactúan, la distribución de los accidentes con respecto a la organización y estructuración espacial, a los usos del suelo y sus mezclas, a las condiciones socioeconómicas y muchas otras interrelaciones espaciales.

En Colombia, el fenómeno de la accidentalidad de tráfico generalmente se aborda con estudios bajo el enfoque de la salud y de la técnica del transporte. La falta de las aportaciones en análisis geográfico, mediante el análisis espacial, demuestra las deficiencias que presentan los resultados de las investigaciones en cuanto al desconocimiento de numerosas variables que describen condiciones y características socioeconómicas de las áreas y zonas de influencia, que inciden notablemente en el fenómeno y que, al mismo tiempo, son impactadas por este. De igual forma se desconocen las interrelaciones entre estas variables y sus elementos espaciotemporales que, en conjunto, son causantes del mismo fenómeno.

La distribución espacial de los accidentes en Bogotá, se asocia con las particularidades o características de las personas que viven o transitan en una zona, lo que da lugar al establecimiento de la concentración o dispersión de estos eventos. Por ejemplo, podría explorarse la distribución espacial de los accidentes de acuerdo con el tipo de usuario de la vía, en función de la especialización física y socioeconómica del espacio; es decir, no es lo mismo una zona dormitorio o residencial con respecto a una zona industrial, administrativa, educativa o de solo circulación vehicular. Igualmente, en otras ocasiones el patrón espacial presenta variaciones en función del tiempo. Estas y otras variables constituyen los flujos para la movilidad, factor determinante en la ocurrencia de los accidentes.

2 Atropello, choque, volcamiento, caída ocupante, incendio, otros. Definición utilizada por el Ministerio de Transporte de Colombia. 


\section{Fundamentos de investigación}

\subsection{El accidente de tráfico como fe- nómeno físico, espaciotemporal}

Según Chías y Luna (1999), un accidente de tráfico se define como un evento espacial y temporal, resultado del movimiento entre personas y vehículos en un espacio determinado que está interrelacionado con otras variables socioeconómicas dinámicas y complejas.

Xumini (2008) lo contextualiza hacia el equilibrio energético de los cuerpos que intervienen en el accidente, y define el accidente de tráfico como un fenómeno físico producido por un desequilibrio energético que procede del movimiento (cinética) y de la posición de los cuerpos (potencial). De entrada se deduce que en el proceso genético de todo accidente de tráfico existe un antecedente genérico: un desequilibrio del movimiento y de la posición de los cuerpos, lo que lo incluye como una acción voluntaria, o sea, homicidio y suicidio utilizando el tráfico vial, provocado a propósito, que conlleva consustancialmente el desequilibrio energético que causará muerte, lesiones y daños.

Desde luego, cuando están en equilibrio el movimiento y la posición de los cuerpos, no puede generarse el desequilibrio energético que se manifiesta en el fenómeno físico. Pero, si se concibe el movimiento de traslación como el estado en el cual un cuerpo se encuentra variando constantemente su posición en el espacio y en el tiempo, o sea, que cambia constantemente de un lugar hacia otro $y$ desde el "ahora" hacia el "después", se comenzará a operar sobre el equilibrio de los movimientos. Por ello, podemos sostener que la energía del movimiento también es la de la posición de los cuerpos, de su variación en el espacio y el tiempo. Luego, un desequilibrio del movimiento es, en esencia, un desequilibrio de la posición de los cuerpos en el espacio, el tiempo, el aquí y el ahora.

De acuerdo con lo referido en la contextualización física de un accidente de tráfico, las formas básicas de los accidentes son desequilibrios de la posición de los cuerpos en el contexto espacio-tiempo o geometría espaciotemporal; que son de la posición de un cuerpo respecto a la normal en el espacio-tiempo - salidas de carriles, calzadas, vuelcos, rotaciones y caídas-; o de la posición de un cuerpo respecto a la de otros cuerpos -impactos, choques-; así como las combinaciones sucesivas de las formas elementales.

Así que es imprescindible investigar sobre cuáles son los elementos y factores que generan estos desequilibrios y que resultan en accidentes de tráfico. Los accidentes tienen un componente territorial, espacial y temporal que se relaciona fuertemente con las características físicas y socioeconómicas del espacio analizado, condición que los determina como un problema no aleatorio sino determinístico de tipo multicausal, causas que al ser identificadas pueden ser manejadas y equilibradas.

De ello se deriva que materializar la seguridad vial exige asegurar el constante $\mathrm{y}$ necesario mantenimiento del equilibrio de elementos y factores, porque su 
ruptura produce el accidente o el peligro inmediato de que ocurra. Desde luego que el no tener estructurados y configurados los sistemas, asegurando el mantenimiento constante del equilibrio, constituye una situación de riesgo permanente.

\subsection{La dinámica geográfica, rela- ción espacio-tiempo como ley fundamental de movilidad}

La descripción geográfica del flagelo, basada en su localización, no puede olvidar su constante relación con el tiempo, con los elementos del tránsito, los cuales son especiales para entender el proceso generador de la movilidad, característica fundamental de la dinámica urbana.
La movilidad, por definición, está indisolublemente unida a espacio, tiempo y sociedad. Entender la constante relación de estos elementos, propicia la deducción de los procesos de la dinámica territorial generadora de esta movilidad, característica esencial del transporte en las zonas, pues su fundamento consiste en el desplazamiento de bienes y personas sobre el territorio.

La Figura 1 visualiza la interrelación espacio-tiempo, para definir la movilidad, dinámica del transporte, asociada a espacio geográfico, pues, de hecho, es también categoría común a las ciencias básicas y sociales, cuya transformación estructura el pensamiento de disciplinas asociadas.

Figura 1. Fundamento de la interrelación espacio-tiempo-transporte-accidentalidad, punto de partida para el análisis geográfico.

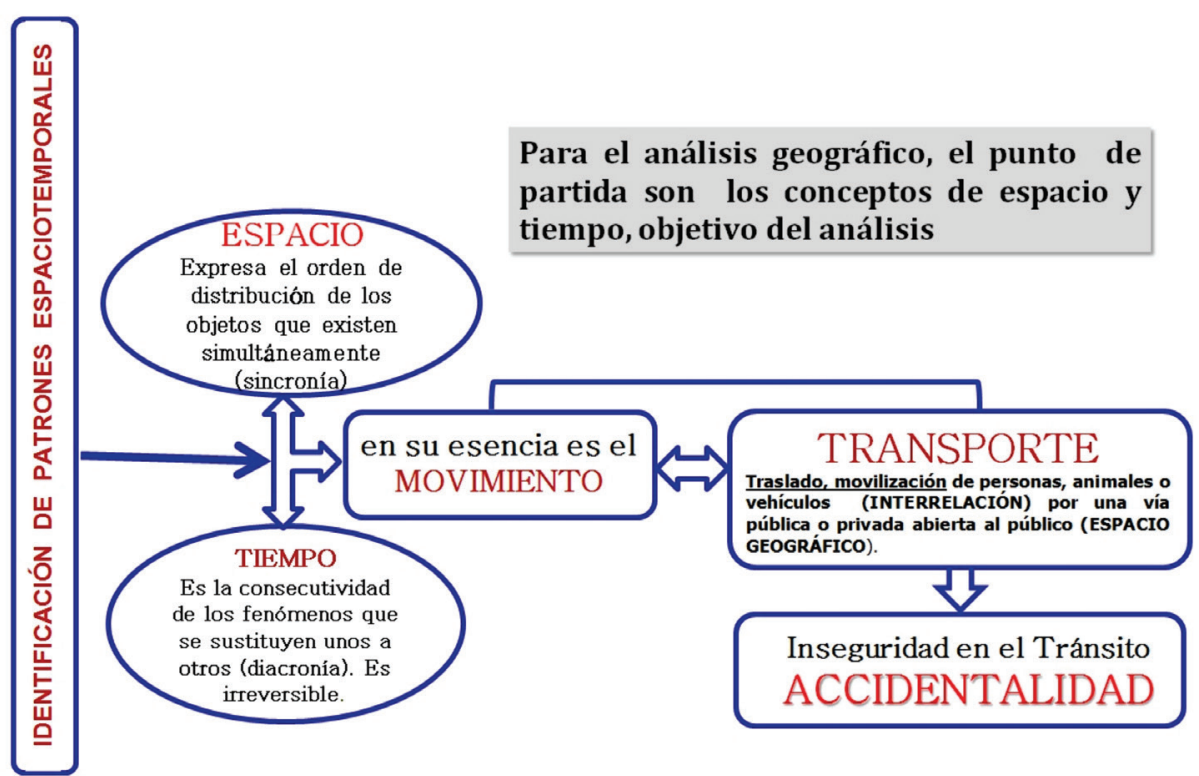

Fuente: elaboración propia. 
La Figura 2 describe la relación de la dinámica geográfica y la movilidad en el transporte, que orienta su mayor interés en los asuntos relacionados con la organización espacial, es decir, con la forma como los individuos y las socie- dades organizan y estructuran el espacio para ajustarlo a sus necesidades de movilidad, y como, a su vez, el transporte va configurando el territorio, el cual es el ejemplo sobresaliente de la reciprocidad del transporte y su geografía.

Figura 2. Fundamento de la interrelación dinámica geográfica. Ley fundamental de movilidad.

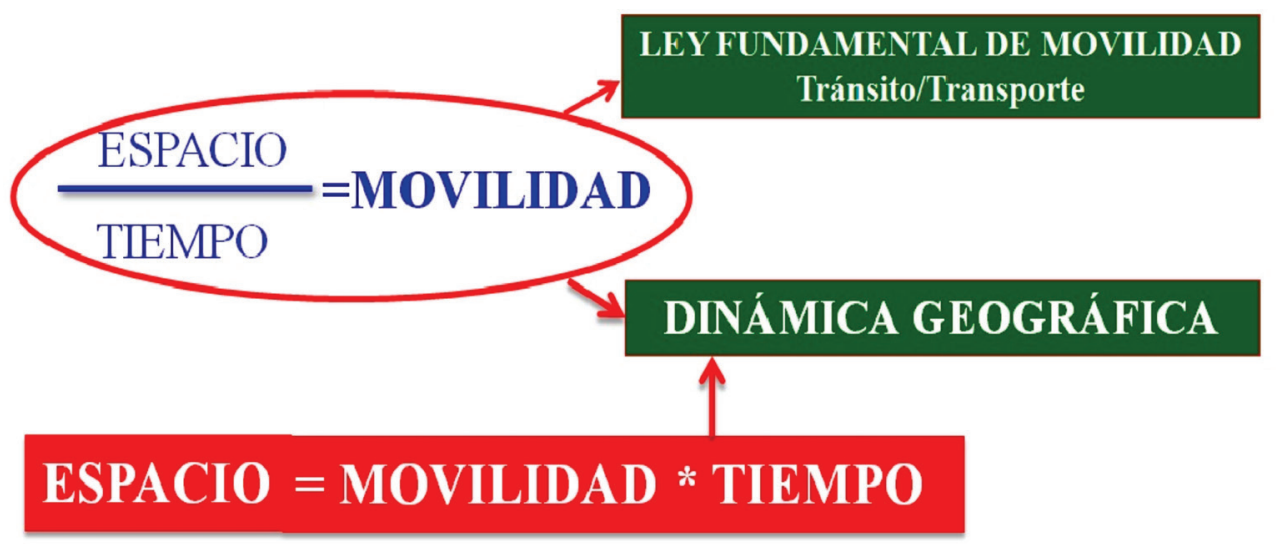

Fuente: elaboración propia.

Este concepto provee una estructura apropiada para analizar, dirigir y orientar las decisiones de localización y de movimientos, al igual que las estructuras espaciales relacionadas con patrones de uso del suelo, localización industrial, comercial, residencial, asentamientos humanos, etc., que armonicen la movilidad en el sistema vial y no generen desequilibrios, desigualdades que se constituyen en los generadores de accidentes de tráfico.

\subsection{La escala de análisis}

Whitelegg, desde 1987, establece la comprensión de los accidentes de tráfico con referencia a una escala de análisis y señala la importancia de centrarse en esta, para dar una respuesta a la reducción de los accidentes. El análisis para la determinación de la escala va a depender de la definición de las zonas o áreas de influencia de la red en la que ocurren los accidentes; sin embargo, cada red tiene una escala de análisis en la que los procesos espaciales que la definen $\mathrm{y}$, a su vez, son definidos por ella, resultan más evidentes (Gioria, 19979). Esta tarea dentro del campo de la investigación requiere de un gran conocimiento del territorio, de los factores socioeconómicos, de la movilidad y la caracterización física, puntos de conexión que estarán enmarcados también dentro del análisis 
de temporalidad, que además incorpora elementos que intervienen en la ocurrencia o posible ocurrencia.

Como lo menciona el Centre for Advance Spatial Analysis (2003),

Los criterios de delimitación geográfica para el estudio de patrones espaciales-temporales establecen que estos pueden efectuarse desde distintas escalas, pues su alcance puede ir desde lo global, lo regional hasta lo local y en cuanto a criterios de delimitación de áreas, estas pueden ir desde las mismas vías o intersecciones hasta condados, regiones y estados.

Para limitar los lugares, pueden considerarse elementos naturales como montañas o ríos, o definirlos en términos geopolíticos en unidades locales, zonales, regionales y de tipo global, como se presenta en la Figura 3. Por último, las características del lugar pueden estar relacionadas con el ambiente tanto físico, como económico y social.

Figura 3. Fundamentación de criterios en la escala geográfica para el análisis espacial.

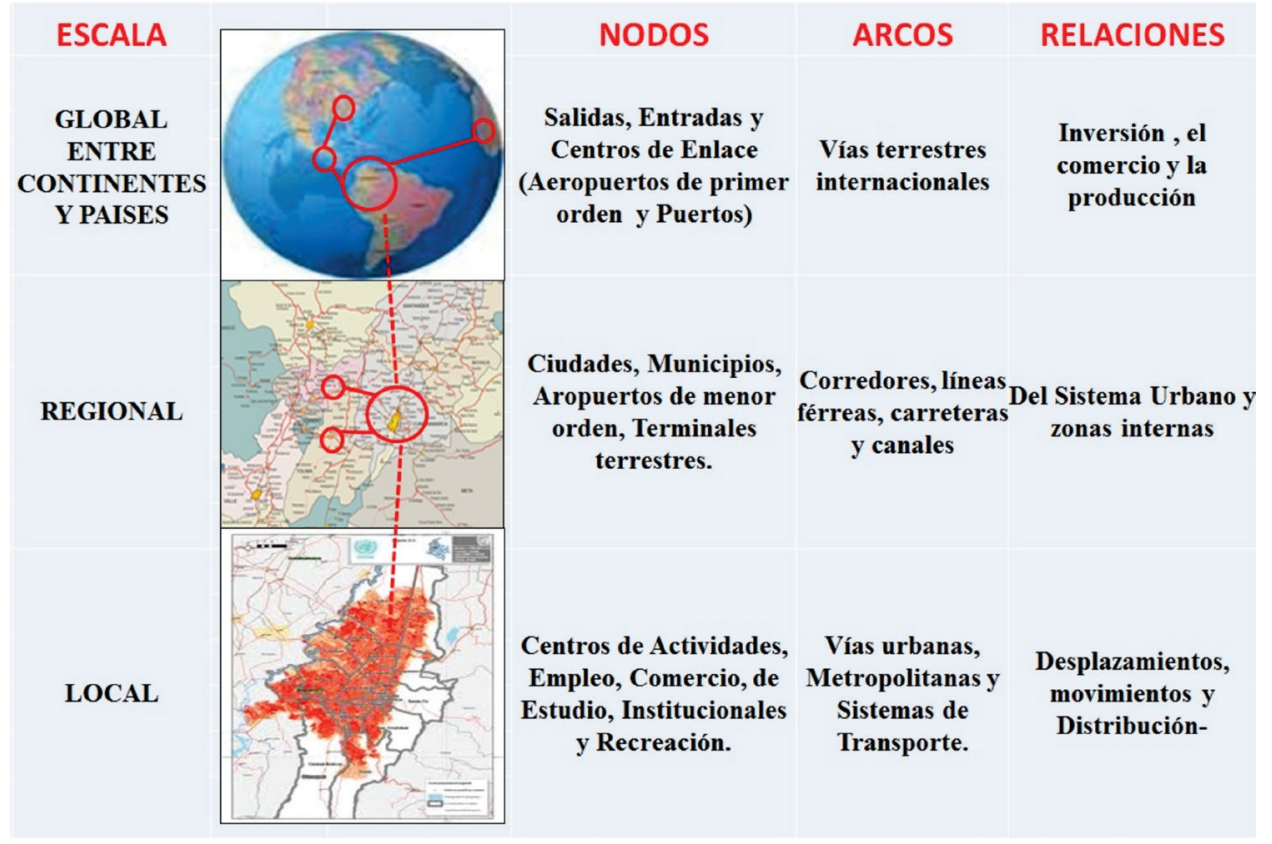

Fuente: elaboración propia.

2.4 La interacción geográfica de variables inherentes al sistema de transporte

No se puede concebir el estudio de los transportes desligándolo de su vital vin- culación con el espacio en el que se inscribe y sobre el que actúan en forma simultánea factores sociales y económicos que lo controlan, llegando a generar condiciones de seguridad e inseguridad en las que se incluyen los fenómenos de 
los accidentes de tráfico. Ullman (citado en W. L. Thomas, jr., et al. 1956) acuñó la idea de la geografía como el estudio de las interacciones espaciales entre zonas, con lo que los fenómenos de transporte toman una importancia central y donde las regiones, diferenciadas tan solo bajo criterios económicos y sociales, se especializan funcionalmente, generando movimientos de personas y mercancías por complementariedad.

La participación de los sistemas de transporte en la dinámica social es determinante, pues tanto la infraestructura como las transformaciones de uso de las necesidades han estado supeditadas a los procesos productivos, culturales y territoriales de una red de transporte. De esta forma, se abordan problemas de lugar, de redes, de regiones y entre naciones, en contraste con su escala local, regional y global.

También Potrykowsky y Taylor (1984) en su investigación, en la que su objeto de estudio fue el transporte tratado como fenómeno o proceso en el espacio, consideraron su estrecha relación con las condiciones físicas, sociales y económicas, demostrando que debe primar como uno de los fundamentos del análisis espacial imprescindible de investigación.

Acotando lo anterior, los sistemas de transporte presentan una serie de unidades organizativas que propician los desplazamientos de personas y mercancías de un punto a otro del espacio, movilidad espacial que reconocemos como flujos. Para Lefebvre (1974), un flujo tiene un origen, un recorrido y un destino, demarcados como terminales o zo- nas de transferencias e integración, que vienen a constituirse como los nodos y arcos de una red de transporte o también denominados elementos neurálgicos de la red, que en su manejo debe ser adaptada al ambiente para que permanezca en equilibrio. El desequilibrio, la desadaptación en el comportamiento de los flujos de la red, viene a ser la razón que desencadena los accidentes de tráfico.

Examinándolo desde una mayor escala, los componentes estructurales del sistema de transporte, definidos por los medios, las redes, las infraestructuras e instalaciones, contribuyen a conocer el tipo, la dimensión y la dirección de los flujos, expresando la interacción entre espacio y tiempo, así como las relaciones equilibradas y desequilibradas que se generan, que serán diferentes en su composición según el espacio socioeconómico territorial en que se desarrollen, relaciones que constituyen el fundamento de la seguridad vial.

Por un sistema de transporte debemos entender un conjunto interactivo de elementos técnicos, organizacionales, económicos y socioambientales, que inciden en la estructura, organización y funcionalidad de todo el sistema urbano regional (Chías, 1997). De ahí que las ciudades son lugares con un alto nivel de acumulación y concentración de las actividades económicas y sociales que en su interrelación generan gran parte de los problemas que se suceden en ellas, lo que las hace ser estructuras espaciales complejas. Los problemas de transporte más importantes suelen estar relacionados principalmente con las zonas urbanas y tienen lugar cuando los 
sistemas de transporte, por diversas razones, no pueden satisfacer las numerosas exigencias de la movilidad especialmente urbana.

Según Wenglesky y Berger (citados por Modenés, 2007; Orfeuil, 2005):

Los problemas del transporte generan desigualdades en las zonas, pues la condición diferencial del acceso a determinadas infraestructuras o a medios de transporte en función de la posición geográfica, lo social, lo demográfico y de ambientes operacionales del tráfico, permite identificar desigualdades de acceso a la movilidad normativa y a las oportunidades que se le asocian. Esto genera que la disposición de los servicios en el territorio no sea homogénea pues se privilegian ciertos espacios y se penalizan otros.

La cobertura territorial de los medios de transporte de uso colectivo, no es igual en todo el territorio, la prestación del servicio es diferencial; en unas zonas solo cubren algunas partes de estas, en especial las que ofrecen aceptables condiciones topográficas; en otras zonas se presta bajo deficientes condiciones de seguridad. Así, la mayor cobertura se da en las áreas más céntricas, mientras que en la periferia es deficiente e ineficiente y es, por consiguiente, el transporte privado en automóvil o bicicleta, el medio más utilizado (Newman \& Kenworthy, 1999), lo cual implica también que es donde las diversas dimensiones del problema de la accidentalidad de tráfico están vinculadas con el predominio y el crecimiento del vehículo privado.

La capacidad se refiere a lo adecuado y sostenible que posee a lo largo de una ruta de transporte, desde su origen hasta su destino o terminales. La capacidad de un sistema de transporte es a menudo limitada por los cuellos de botella que se forman en el espacio físico o infraestructura o en la circulación de los flujos, en un tiempo dado (Tranportation Research Board TRB, 2000). Se generan otros problemas graves como la congestión del tráfico, uno de los problemas más frecuente de las aglomeraciones urbanas, particularmente vinculado con el crecimiento del uso del vehículo particular en sus diferentes tipos, incidiendo en altas tasas de motorización, altos niveles de contaminación y altos índices de accidentes de tráfico, resultados de la deficiencia e ineficiencia en la prestación de servicios de transporte público colectivo.

La Tabla 1 resume las variables que fundamentan el análisis espacial en los sistemas de transporte y que orientan la investigación.

La falta de planificación en las áreas urbanas ha generado en forma continua que la oferta de infraestructura no sea capaz de suplir la necesidad de la demanda y no haya podido con el crecimiento de los flujos vehiculares. Durante las horas pico, gran parte de los sistemas de transporte público es utilizada a su máxima capacidad o la excede, se opera bajo saturación, lo que crea incomodidad e insatisfacción para los usuarios, e incentiva el uso del vehículo particular. La falta de acciones globales, regionales y locales para desalentar 
Tabla 1. Variables geográficas del sistema de transporte que fundamentan el análisis de accidentes de tráficoFuente: elaboración propia.

\begin{tabular}{|c|c|}
\hline Variable & Interacción geográfica \\
\hline $\begin{array}{ll}\text { LA } & \text { CAPACI- } \\
\text { DAD } & \end{array}$ & $\begin{array}{l}\text { 1. Congestión de tránsito. Uno de los problemas más frecuente en las } \\
\text { grandes aglomeraciones urbanas. } \\
\text { 2. Insuficiencia del transporte público. Parte de los sistemas de trans- } \\
\text { porte público es utilizado a su máxima capacidad o es utilizado. } \\
\text { 3. Las dificultades para los peatones y la pérdida del espacio público } \\
\text { para peatones y otros usuarios. }\end{array}$ \\
\hline $\begin{array}{l}\text { LA TRANSFE- } \\
\text { RENCIA }\end{array}$ & $\begin{array}{l}\text { 1. Los impactos ambientales y el consumo de energía. } \\
\text { 2. Demoras y pérdidas económicas. } \\
\text { 3. Dificultad para peatones y otros usuarios. Pérdida de accesibilidad. }\end{array}$ \\
\hline $\begin{array}{l}\text { LA INTEGRA- } \\
\text { CIÓN }\end{array}$ & $\begin{array}{l}\text { 1. Cambios en los usos del suelo y actividades. } \\
\text { 2. Demoras y pérdidas económicas } \\
\text { 3. Pérdidas en la distribución de la demanda. } \\
\text { 4. pérdidas en la accesibilidad y facilidad de uso }\end{array}$ \\
\hline
\end{tabular}

el uso del automóvil privado, ha generado fenómenos de congestión insostenibles. Las altas tasas de motorización han aumentado la demanda de espacios para circular y para estacionar, lo que ha creado problemas de utilización del espacio, en particular en las zonas céntricas y de comercio (TRB, 2006). Estas situaciones se traducen en desequilibrios de la red de transporte, lo que resulta en accidentes de tráfico.

La globalización y la materialización de la economía han dado lugar a cantidades crecientes del movimiento de carga dentro de las ciudades, pues comúnmente el tráfico de carga comparte la infraestructura con la circulación de pasajeros y peatones, generando mayores desequi- librios e inestabilidad en la movilidad. Por consiguiente, el transporte de mercancías se ha convertido en un problema en las zonas urbanas, debido a la falta de previsión y provisión de una infraestructura física para ello. Los altos niveles de congestión que se generan, afectan también la movilidad de peatones y ciclistas, pues en el diseño físico de la infraestructura se evidencia una ausencia de consideración hacia esta población. El incremento del tráfico genera carriles y zonas peatonales ocupadas continuamente con vehículos estacionados (Cerquera \& Pérez, 2007), lo que tiene un impacto adverso en el aprovechamiento del total de la capacidad de las zonas (Litman, 2009) y potencia uno de los 
flagelos de las zonas urbanas, como los accidentes, con un progresivo número de muertos y heridos, especialmente en los países en desarrollo (Rey \& Cardozo, 2009). Los accidentes representan una parte significativa de las demoras recurrentes en la circulación, y conforme aumenta el tráfico, los accidentes van en aumento. En América Latina, la gente se insensibiliza cada vez más ante el fenómeno (Peden et al., 2004).

La ocupación de las aceras y ciclovías con ventas y mercados tiene un impacto adverso en la movilidad de peatones y bicicletas; en muchos casos, estas actividades han generado asentamientos que crean problemas sociales. Las congestiones de los flujos de tráfico afectan la salud de los diferentes grupos sociales y el uso del espacio de la vía; más tráfico impide la interacción, las actividades sociales y comunitarias urbanas, porque aunque la gente quiere caminar, se ve limitada por los ciclos semafóricos peatonales que van a ser cada vez menores cuando el tráfico es alto (Cebollada \& Miralles, 2003), lo que incide en una de las causales altas de accidentes, como es el atropellamiento de peatones.

Los puntos de transferencia permiten la interconexión entre los diferentes medios de transporte, un papel habitualmente atendido por los centros de enlace o puertos de entrada o salida en los que se generan problemas críticos en la circulación, tales como demoras, contaminación, incluido el ruido, desencadenando accidentes, lo que se convierte en un grave obstáculo para la calidad de vida e incluso la salud de las poblaciones urbanas.
La integración implica conseguir un sistema de transporte que permita viajes sin fisuras que opere bajo condiciones de seguridad y eficiencia. En consecuencia, se trata de ofrecer un abanico diversificado de servicios de movilidad que satisfaga, lo máximo posible, las necesidades individuales de cada usuario. La realidad es que la eficacia de las redes de transporte depende de su accesibilidad y facilidad de uso, lo cual exige una coherencia y una buena integración entre los servicios, así como una continuidad física y operativa de la red para aprovechar las ventajas de cada modo de transporte y que los flujos se hagan más confiables y seguros. Si el sistema de transporte no está bien integrado con sus mismos medios de transporte, con los usos y en las funciones del territorio, es difícil que garantice el acceso a cualquier punto de la ciudad en toda la franja horaria (Miralles-Guash, 2002). Este objetivo se puede lograr con el transporte intermodal, pero se desprenden problemas tipo, de usos del suelo, de diseño geométrico, mobiliario urbano y de distribución de la demanda.

\subsection{La interacción de variables geo- gráficas de causa local}

La geografía de la accidentalidad describe los fuertes vínculos del análisis de los accidentes de tráfico y el ámbito geográfico que permite de igual forma identificar, reconocer y evaluar con mayor detalle, según la clase de accidente, sitios, áreas y corredores inseguros y de alto riesgo para luego poder establecer patrones tipo con indicadores que describen el evento de acuerdo con la ma- 
yor o menor incidencia de los elementos $\mathrm{y}$ factores que se correlacionan e interactúan para que estos ocurran.

De ahí que el estudio de los accidentes de tráfico requiere no solo del análisis de la globalidad que caracteriza los sistemas de transporte, pues es necesario investigar los problemas inherentes a su directa y específica localización que impacta la dinámica espacial e identifica la correlación con variables que pueden ser la causa precisa de su origen. El accidente debe dejar de ser visto como evento unicausal, aleatorio e imprevisible, puesto que los siniestros de este tipo ocurren bajo circunstancias complejas y multicausales (Haddon, 1980). Es posible analizar el problema a diferentes escalas, en función de la precisión de la información original, y antes que considerarse como un error humano, debe entenderse como un problema social de significativos antecedentes y repercusiones de tipo económico y de salud pública, que para ser tratado e investigado debe incluir puntos de vista integrales y multidisciplinarios.

Es así como los análisis han determinado los fuertes vínculos de los accidentes de tráfico y factores físicos, sociales y económicos de los sitios (barrios, tramos viales e intersecciones) donde ocurren, debido a que el movimiento - sea de peatones o de vehículos- está en función del sistema de usos del suelo, de las actividades (comercio, trabajo, escuelas, instituciones, militar) que se desarrollen, del tipo de población, de la configuración (geometría y ubicación) del sector, en fin, de variables de tipo geográfico que identifican con mayor precisión las áreas de influencia impactadas por el fenómeno.

Mediante el reconocimiento y la delimitación del máximo de estas variables que intervienen, bajo una escala local, se pueden definir las circunstancias en que los accidentes suceden y se obtienen los patrones de localización y de ocurrencia, y, por lo tanto, se puede predecir con mayor probabilidad su acaecimiento y no tan solo por medio de la determinación de un elemento causante ${ }^{3}$ con la identificación de una única causa (sistema unicausal) y alguna que otra característica, tal y como se ha acostumbrado en el campo del transporte y la salud.

En la Figura 4 se establece el esquema marco de delimitación de variables de causas a una escala local.

En la Tabla 2 se presenta la delimitación con definición e interrelación de las variables de ámbito local que intervienen en el análisis espacial de accidentes. 
Figura 4. Delimitación de variables de ámbito geográfico que intervienen en la ocurrencia de accidentes.

\section{ANÁLISIS ACCIDENTES E INCIDENTES DE TRÁNSITO}

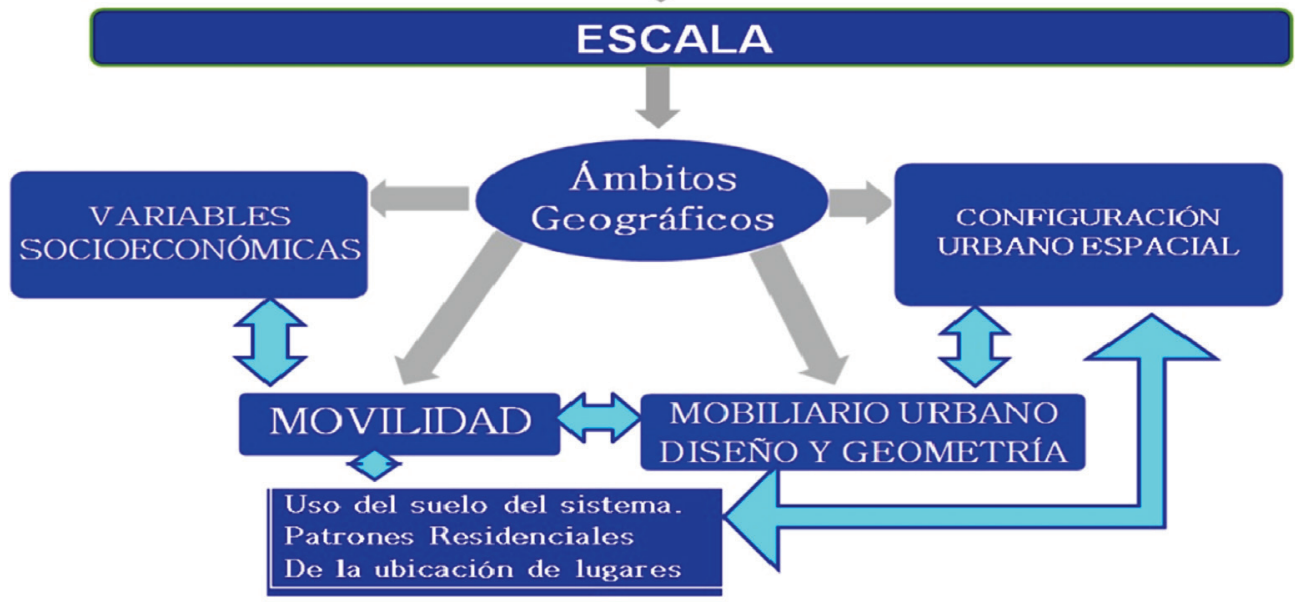

Fuente: elaboración propia.

Tabla 2. Interacción y delimitación espacial de variables y factores de ámbito geográfico que inciden en la accidentalidad.

\begin{tabular}{|l|l|l|}
\hline Variable & Factores & Interacción geográfica \\
\hline MOVILIDAD & Conductor & En función directa de: \\
& Peatón & Los desplazamientos, demandas de orígenes y \\
Pasajero & destinos; \\
& Vía & $\begin{array}{l}\text { la localización de orígenes y destinos; } \\
\text { un SITP: sistema integrado de transporte públi- } \\
\text { Ciclovía }\end{array}$ \\
& Acera o andén & $\begin{array}{l}\text { volúmenes de peatones, de vehículos particula- } \\
\text { res; }\end{array}$ \\
& Vehículo & usos del suelo, de sus mezclas; \\
& Autoridad e institución & las actividades desarrolladas y de sus mezclas; \\
& & la densidad y tipo de red vial. \\
\hline
\end{tabular}




\begin{tabular}{|c|c|c|}
\hline $\begin{array}{l}\text { CONFIGU- } \\
\text { R A C I Ó N } \\
\text { U R B A N O } \\
\text { ESPACIAL }\end{array}$ & $\begin{array}{l}\text { Zona o área de ocurren- } \\
\text { cia } \\
\text { Vía } \\
\text { Ciclovía } \\
\text { Andén o acera } \\
\text { Puentes peatonales } \\
\text { Zonas laterales. }\end{array}$ & $\begin{array}{l}\text { En función directa de: } \\
\text { Configuración de manzanas, de barrios, de sec- } \\
\text { tores; } \\
\text { configuración de la red vial, radial, rectangular; } \\
\text { pendientes, anchos de calzadas, carriles, aceras } \\
\text { peatonales; } \\
\text { crecimiento físico urbanización. Longitudinal, } \\
\text { triangular, rectangular. Ciclovías, aceras, puen- } \\
\text { tes, barandas peatonales. }\end{array}$ \\
\hline $\begin{array}{l}\text { SOCIOECO- } \\
\text { NÓMICAS }\end{array}$ & $\begin{array}{l}\text { Del conductor } \\
\text { del peatón o } \\
\text { del pasajero. }\end{array}$ & $\begin{array}{l}\text { En función directa de: } \\
\text { Densidad poblacional; } \\
\text { estrato socioeconómico, ingresos; } \\
\text { grado de educación y dedicación actividades. }\end{array}$ \\
\hline $\begin{array}{l}\text { ELEMENTOS } \\
\text { Y MOBILIA- } \\
\text { RIO URBA- } \\
\text { NO, DISEÑO } \\
\text { Y GEOME- } \\
\text { TRÍA }\end{array}$ & $\begin{array}{l}\text { Paraderos, bolardos, se- } \\
\text { ñales, cabinas, elemen- } \\
\text { tos laterales buzones, } \\
\text { árboles, barreras de } \\
\text { tráfico. }\end{array}$ & $\begin{array}{l}\text { En función directa de: } \\
\text { Diseño de áreas y geometría de mobiliario ur- } \\
\text { bano; } \\
\text { diseño y localización de elementos del mobi- } \\
\text { liario urbano; } \\
\text { diseño y localización de elementos de zona } \\
\text { central y lateral. }\end{array}$ \\
\hline
\end{tabular}

Fuente: elaboración propia.

\section{El área de estudio, Bogotá D. C., en el contexto de los fun- damentos analizados}

\subsection{El área de estudio, Bogotá, D.C., en el contexto del fundamento de su sistema de transporte}

Bogotá -con una población en crecimiento casi constante en los últimos años (Dane, 2011), y con la falta de capacidad del sistema de transporte público colectivo-, viene generando grandes problemas de congestión, en los que incide el aumento acelerado del tráfico au- tomotor particular (Figura 5 y Tabla 3). Fenómeno este que comúnmente aqueja a las urbes latinoamericanas (Thomson, 2007), por el incremento de la cantidad de desplazamientos hacia y desde los lugares de residencia a los sitios de trabajo, centros comerciales, financieros e institucionales, sin poseer una cobertura suficiente y eficiente con un sistema integrado de transporte público que permita un traslado rápido, cómodo y seguro.

En el país, y sobre todo en los entes planificadores, especialmente los de las áreas urbanas, se cree que la panacea a los problemas de congestión de una zona, es privilegiar la inversión estrictamente hacia la construcción de vías, 
Figura 5. Crecimiento parque automotor.

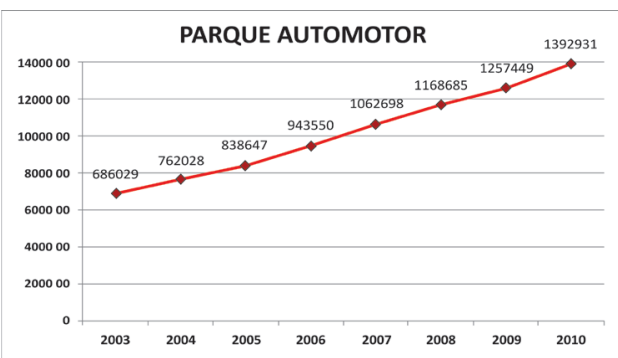

Fuente: elaboración propia, a partir de datos de la SDM (2010).

con el objeto de facilitar la conexión entre áreas. Ahora bien, no se desconoce que la estrategia en sus primeros momentos puede generar desarrollo, pero a costa del crecimiento acelerado del parque automotor de vehículos particulares, de transporte público individual, por el incentivo de los desplazamientos en este tipo de automotores, el aumento de la misma congestión, demoras y, en consecuencia, el incremento de la inseguridad vial, pues el bajo control en la operación de este colectivo de vehículos incide en los altos niveles de accidentalidad vial.

Si bien se han implementado programas con acciones sobre la demanda de movilización en transporte privado y público individual, uno de ellos, el denominado "pico y placa"4, que se efectuó para resolver los problemas de congestión y movilidad de los últimos años, generó el incremento del uso del vehículo privado y contribuyó al crecimiento del

4 Programa que establece la restricción de la circulación de vehículos por períodos de acuerdo con el número de placa. Decretos Distrital 007 de 2002, 180 de 2004, 142 de 2006 de Alcaldía Mayor de Bogotá. http://www.alcaldiabogota.gov.co/sisjur/normas/Norma1.jsp?i=4590
Tabla 3. Crecimiento población e índice motorización 1985 a 2010

\begin{tabular}{|c|c|c|c|c|c|c|}
\hline Año & vehículos & $\begin{array}{c}\text { Tasa Quinquenal } \\
\text { Veh. (\%) }\end{array}$ & Población & $\begin{array}{c}\text { Tasa } \\
\text { Quinquenal } \\
\text { Pob. (\%) }\end{array}$ & $\begin{array}{c}\text { Veh/1000 } \\
\text { hab }\end{array}$ & Hab/veh \\
\hline 1985 & 274000 & & 4200226 & & 65 & 15.3 \\
\hline 1990 & 357000 & 30.29 & 5013154 & 19.35 & 71 & 14.0 \\
\hline 1995 & 498000 & 39.50 & 5678342 & 13.27 & 88 & 11.4 \\
\hline 1999 & 534109 & & 6050000 & & 88 & 11.3 \\
\hline 2000 & 577844 & 16.03 & 6437842 & 13.38 & 90 & 11.1 \\
\hline 2005 & 838647 & 45.13 & 7029928 & 9.20 & 119 & 8.4 \\
\hline 2008 & 1168685 & & 7155052 & & 163 & 6.1 \\
\hline 2009 & 1257449 & & 7200000 & & 175 & 5.7 \\
\hline 2010 & 1392931 & 66.09 & 7247000 & 3.09 & 192 & 5.2 \\
\hline
\end{tabular}

Fuente: elaboración a partir de datos de la SDM y DANE (2010).

transporte privado, por lo que exige la construcción de mayor cantidad de vías y áreas de estacionamiento, en lugar de presionar por acciones estructurales en el transporte público colectivo y masivo, que son, en términos de sentido común y de experiencia de muchos países como Brasil, México y otros (CAF, 2011), que ya recorrieron el mismo camino, las mejores acciones en el ámbito urbano para tener una movilidad sostenible y reducir índices de accidentalidad y de contaminación.

Los datos de la Tabla 3 presentan el alto incremento del parque automotor que se ha presentado en Bogotá, de 838.647 automotores, vehículos y motocicletas del año 2005 a 1.392.031 en el año 2010, lo cual representa ingresos de vehículos, en promedio superiores a 120.000 vehículos por año (Secretaria Distrital de Planeación SDP, 2009), equivalentes a $720 \mathrm{~km}$-carril adicionales de uso anual sobre la red distrital (aumentos anuales promedios del $10 \%$ e incremento del $66 \%$ en los últimos seis años). Este comportamiento periódico socava permanentemente la capacidad, deteriora los escasos puntos de transferencia e in- 
tegración de cualquier sistema, más aún si no se opera con sistemas de transporte masivo y con una estructura intermodal que optimice los desplazamientos para lograr una eficiente movilidad y seguridad vial en la ciudad.

Ahora, el análisis de la caracterización de la distribución temporal que presenta la accidentalidad en la capital (Figura 6) demuestra que en los períodos de mayor volumen vehicular y en consecuencia de mayor congestión, los conocidos como

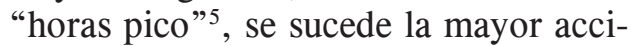
dentalidad, comportamiento que sustenta la incidencia que tiene el incremento del parque automotor sobre los índice de accidentalidad. Es así como en los años 2008 a 2011, el sábado, día cuando no existen restricciones de circulación ${ }^{6}$, lo que hace que se presenten períodos de alta congestión - a veces mayores que los de un día normal entre semana- (SDM, 2011), se constituye en el día de la semana que presenta mayores accidentes graves, y entre las cinco y las ocho de la mañana, y las cuatro de la tarde a las siete de la noche, son las horas de mayor congestión (SDM, 2011) de un día típico normal, en que se registró la mayor cantidad de accidentes.

Figura 6. Distribución temporal de la accidentalidad en Bogotá D.C. 2008 a 2011.

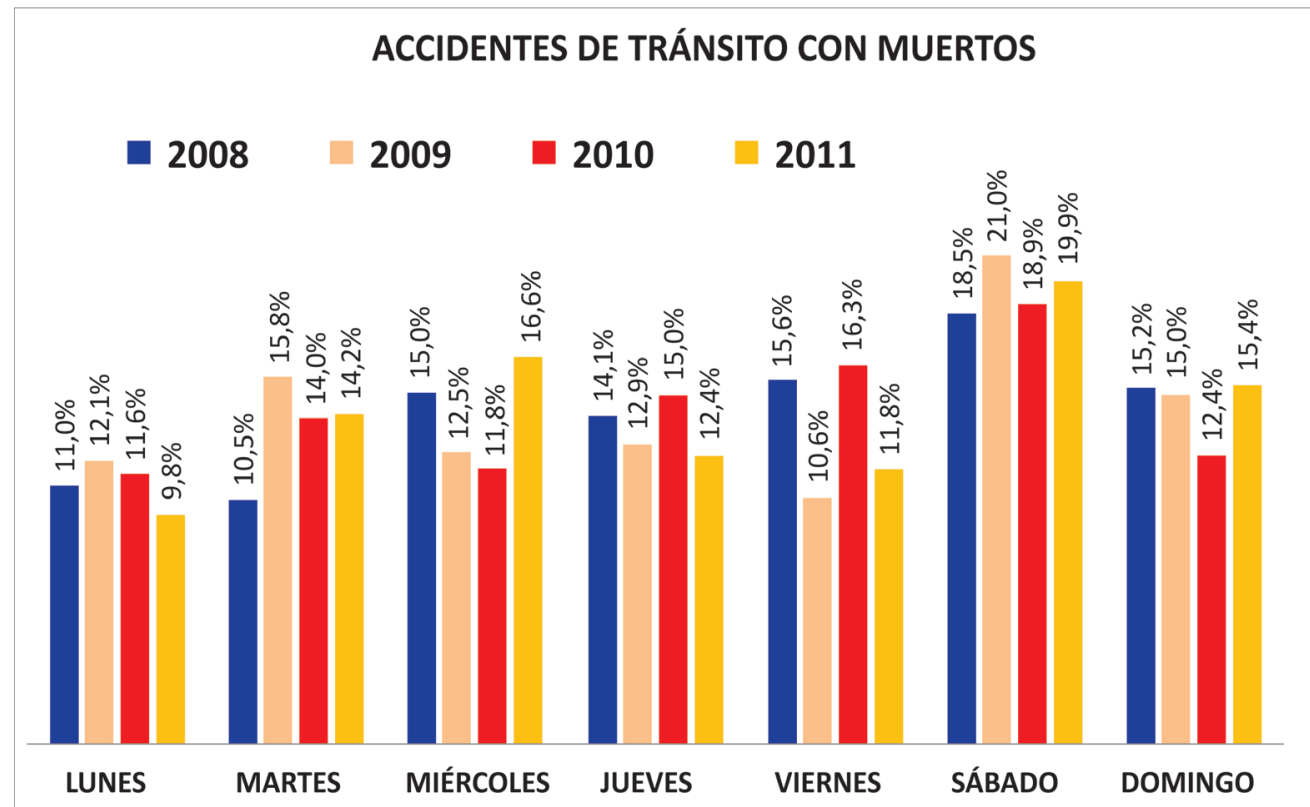

5 Días y horas que presentan los mayores volúmenes de flujos vehiculares.

6 Se permite la circulación de todos los vehículos. No existen restricciones de "pico y placa". 


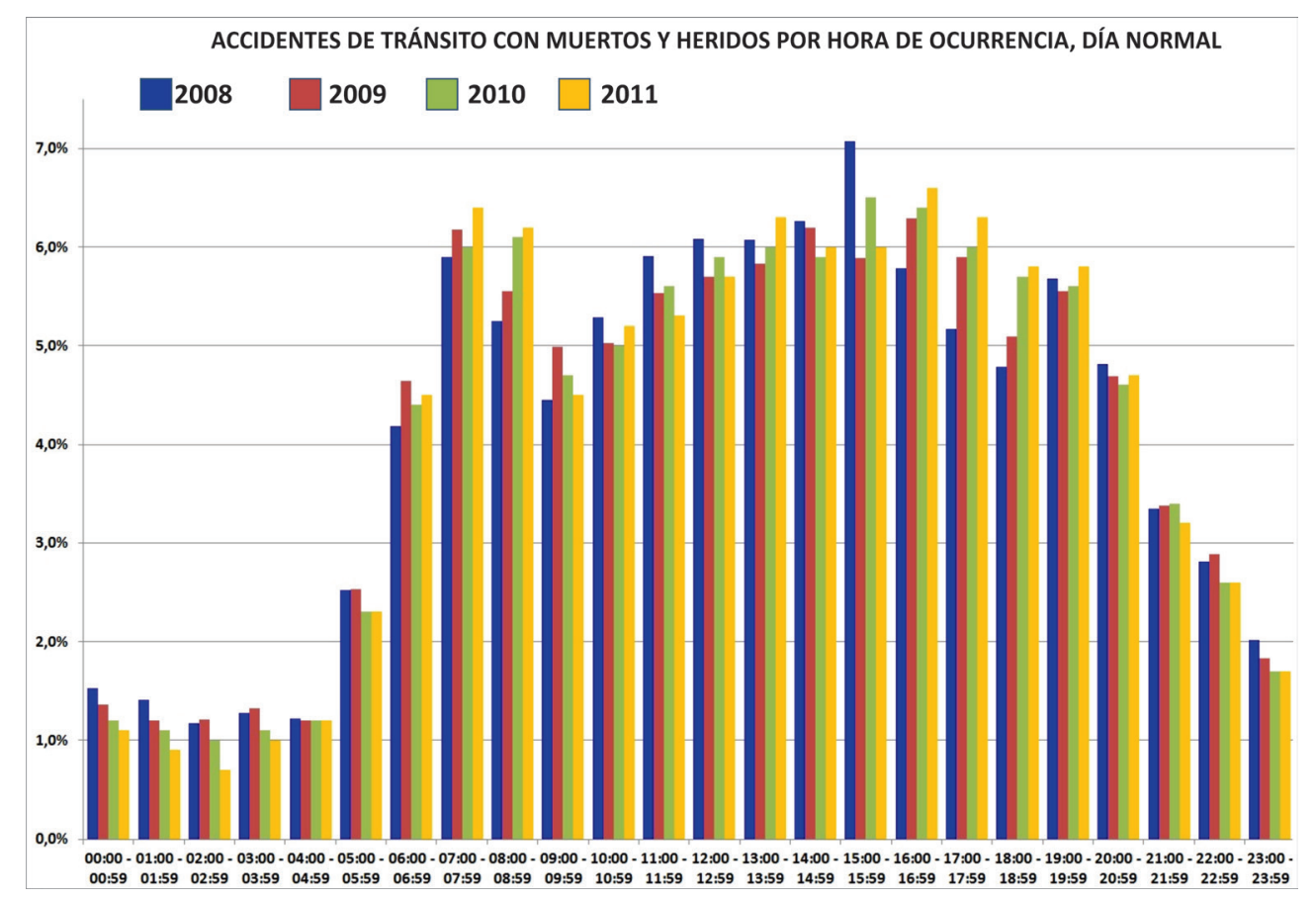

Fuente: elaboración propia a partir de datos suministrados por SDM (2011)

En consecuencia, ante un parque automotor que no deja de crecer, una demanda de desplazamientos en aumento, por cuanto muchas de las funciones urbanas son altamente centralizadas, una capacidad que día a día es insuficiente, con cobertura deficiente en accesibilidad, nodos de transferencia e integración intermodal, es lógico que se presenten problemas neurálgicos de congestión con accidentes. Este contexto revela la falta de una planificación ordenada, integral y sostenible del territorio en el transporte, con base en la investigación espaciotemporal de zonas de riesgo por la ocurrencia de accidentes de tráfico, que profundice y revele la raíz del problema. Esta falta se traduce en la deficiencia del establecimiento e implantación de políticas y estrategias con objetivos claros de calidad y equidad en el servicio de transporte hacia todos los usuarios (Morera, 2011), que den un impulso real a la intermodalidad, la transferencia, la integración y la accesibilidad de las áreas, especialmente donde habita la población menos favorecida que demanda e interviene en la función de la movilidad. Ello genera que estas comunidades muy difícilmente puedan enfrentar airosamente situaciones sociales y económicas cada vez más complejas, aumentando así los niveles de segregación, de morbilidad y mortalidad generada por la inseguridad e inequidad en la movilidad.

Las áreas de Bogotá donde se producen los accidentes de tráfico con mayor frecuencia, vienen generando patrones de riesgo generalizado en sectores y corre- 
dores viales internos principales ${ }^{7}$. Las figuras 7 y 8 contienen los mapas de los años 2010 y 2011 con las áreas de las localidades que presentan los mayores focos de concentración y densidad de accidentes de tráfico y donde se localizan las zonas en las que existen problemas de transferencia e integración en el sistema de transporte, como es el caso de las localidades de Fontibón, Engativá, Kennedy, Suba y Usaquén, que corresponden a los sectores donde se encuentran localizadas las zonas de transferencias del aeropuerto El Dorado (con las avenidas Jorge Eliecer Gaitán y José Celestino Mutis), los tramos de integración vial intermunicipal con Chía (autopista Norte), Soacha (autopista Sur), Funza y Mosquera (José Celestino Mutis, calle 80, del Ferrocarril). Esta fundamentación inicial orienta el análisis geográfico para continuar con la investigación a profundidad de las variables de causa local en cada uno de estos sectores.

\subsection{El área de estudio, Bogotá, D.C., en el contexto del fundamento de variables de causa local}

Los accidentes de tráfico que ocurren con mayor frecuencia en Bogotá D. C. son los choques y los atropellos (años 2010 y 2011), estado que como se había indicado viene generando un riesgo generalizado en los principales sectores y corredores viales de zonas y áreas internas de la capital.

Los mapas de las figuras 7 y 8 muestran la concentración de accidentes en localidades y corredores viales ocurridos en el año 2010 y 2011, definida por medio

$7 \quad$ Zonas y corredores viales que son neurálgicos para la movilidad, según la Secretaría Distrital de Movilidad. de las técnicas de elipse de distribución direccional de desviación estándar (Scott \& Janikas, 2008) y densidad (Acuña, 2000; Moreno, 1991, Xie and Yan J., 2008). Ahí se observan la distribución direccional, dispersión y concentración de los eventos en los sectores donde se agrupan y los focos de densidad de estos, que van a orientar el estudio de otros factores y elementos que intervienen e interactúan, como su configuración, organización y distribución espacial, los usos del suelo y sus mezclas, las condiciones socioeconómicas y muchas otras interrelaciones espaciales. Es el caso de las localidades del centro, Santa Fe, Candelaria y Antonio Nariño, donde viene ocurriendo la mayor concentración de atropellos y, además, son las que mayor problema presentan en su capacidad, nivel de servicio, en su configuración urbana espacial y especialmente en el diseño y geometría de su red vial y mobiliario urbano.

Se muestra que varias de las zonas afectadas por los accidentes en el año 2010, lo continúan siendo en el año 2011, con densidades importantes, generando delicados impactos de mortalidad y morbilidad, que se traducen en conflictos sobre los puntos estratégicos de movilidad de la capital.

Esto revela una problemática constante con tendencias a empeorar (por el crecimiento del parque automotor), y es de tal gravedad que si no se introducen estrategias en los planes de desarrollo y se tratan en su real dimensión, como una de las problemáticas esenciales, Bogotá tendrá cada vez más un panorama insostenible de altos niveles de accidentalidad, sufragando costos que lesionan su desarrollo día a día. 
Figura 7. Áreas de concentración, distribución y densidades de accidentes generados por problemas en el sistema de transporte y variables de causa local. Año 2010.

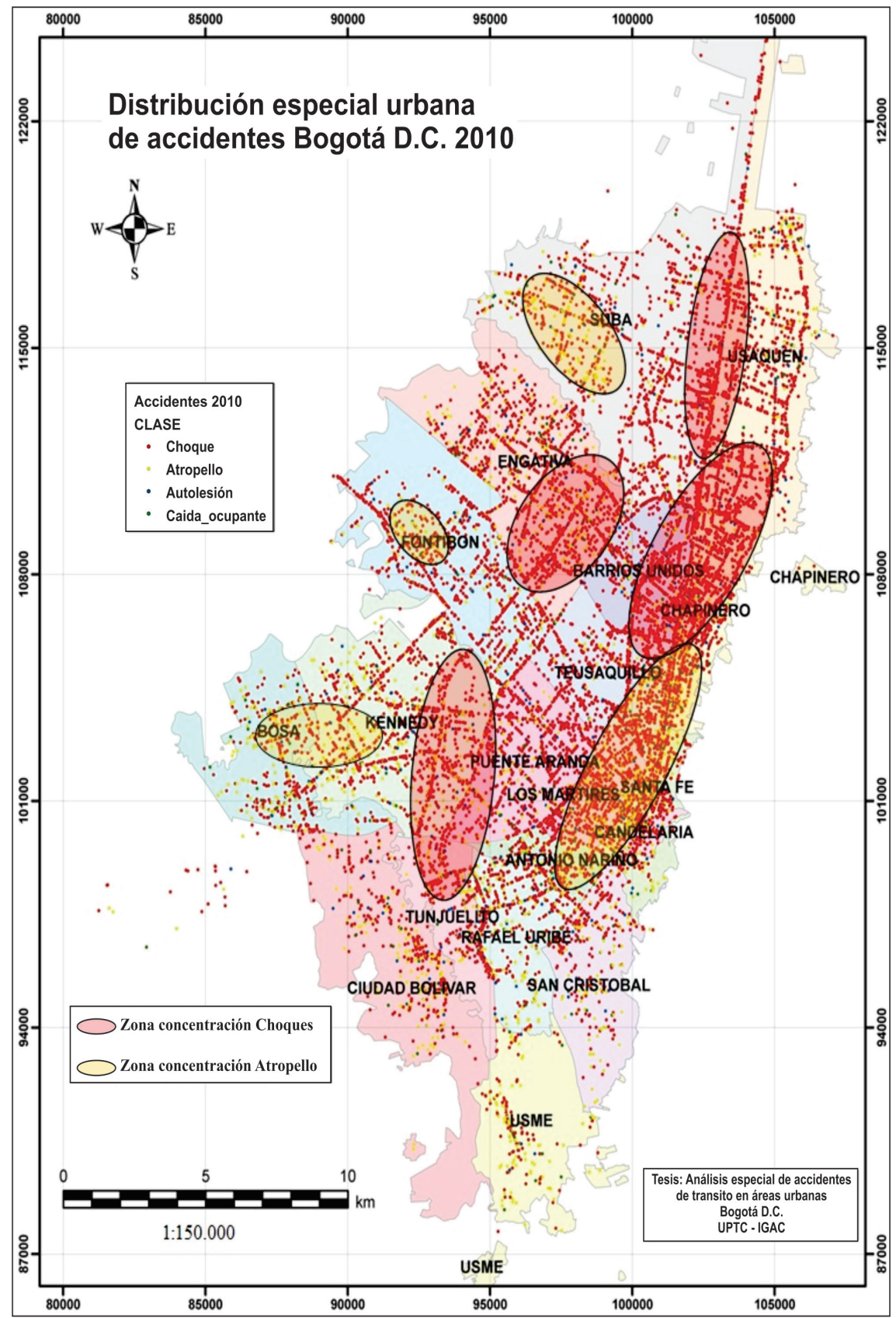




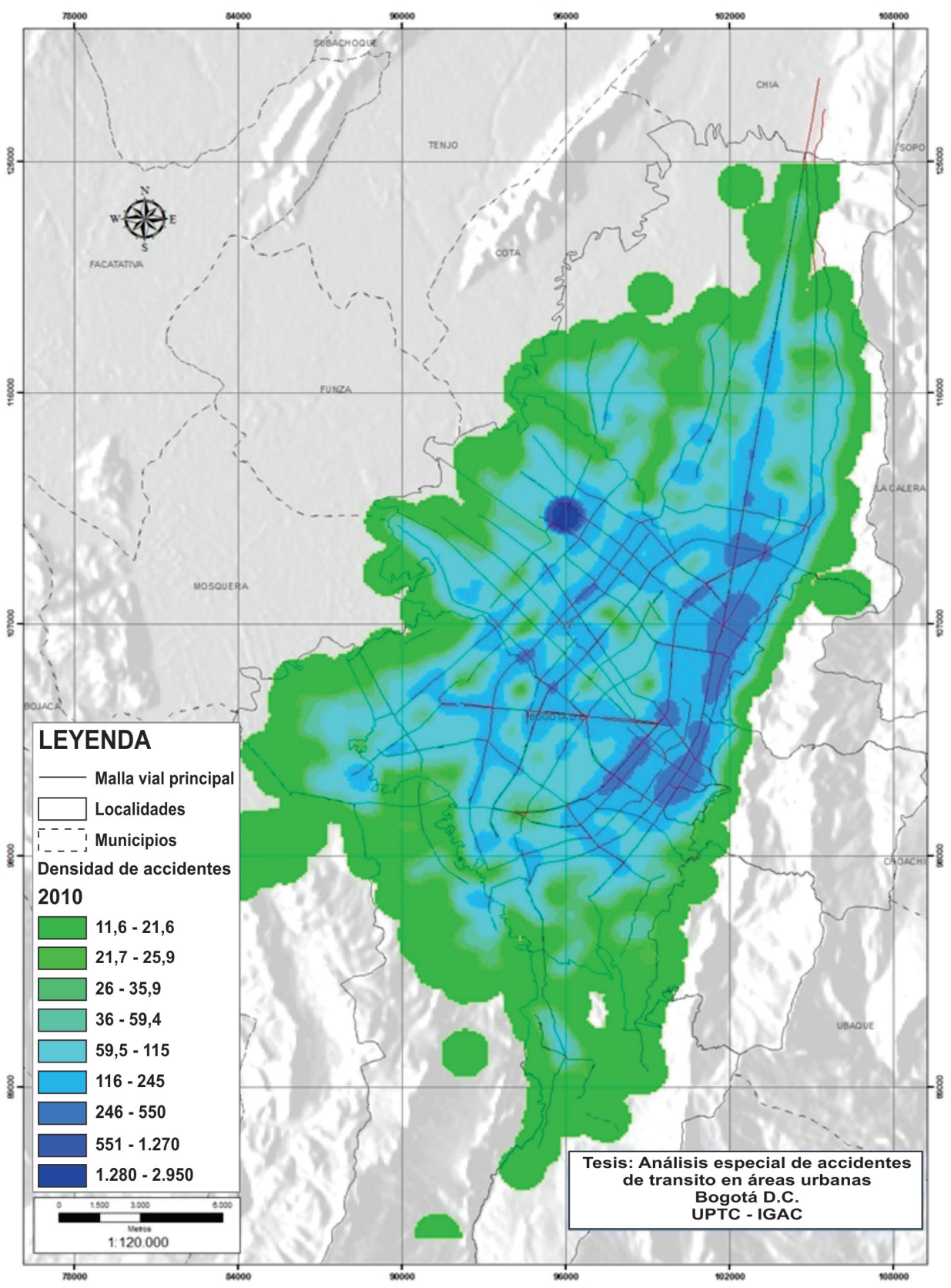

Fuente: elaboración propia 
Figura 8. Áreas de concentración, distribución y densidades de accidentes generados por problemas en el sistema de transporte y variables de causa local. Año 2011.

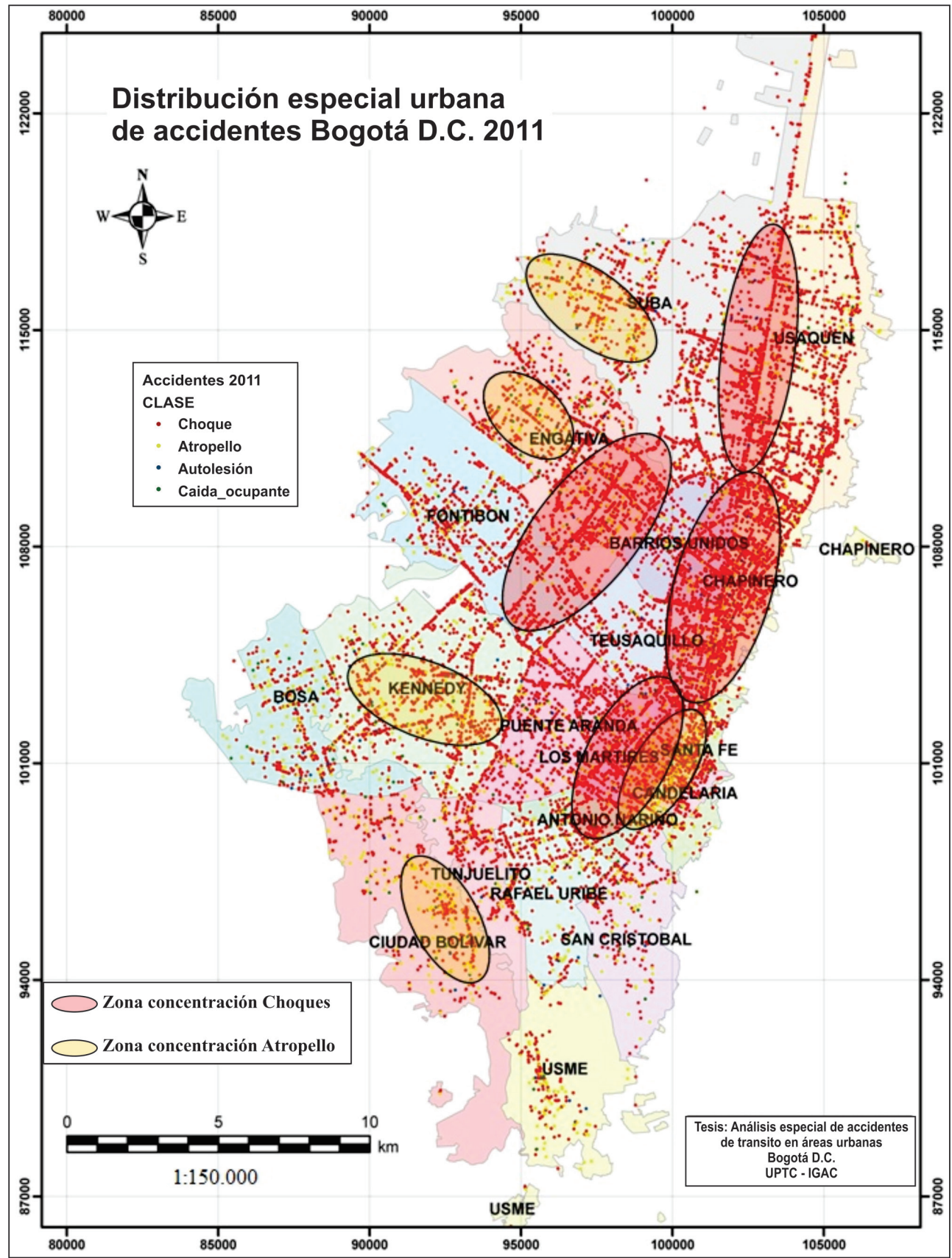




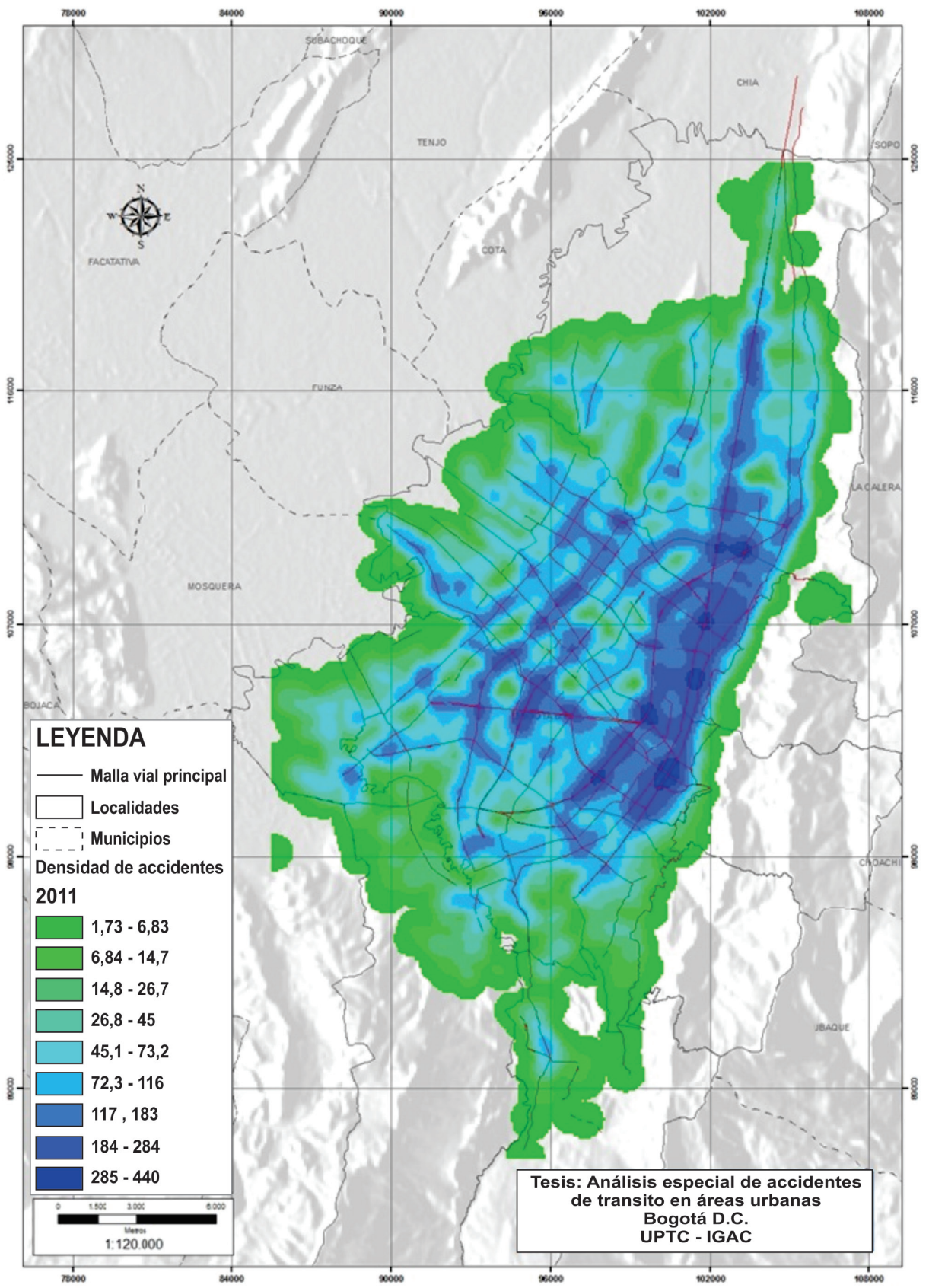

Fuente: elaboración propia 


\section{Conclusiones}

La fundamentación del análisis geográfico en la ocurrencia de los accidentes de tráfico, aporta elementos clave para la investigación y dirige la identificación de variables bases, que caracterizan el acaecimiento de los accidentes, así mismo sustenta la definición de patrones territoriales en el área urbana de Bogotá D.C., que orientarán luego las programaciones futuras que se formulen de las intervenciones, para prevenir y mejorar la salud y bienestar de la población.

Las variables geográficas contextualizadas en los sistemas de transporte y dentro de un ámbito localizado, que interactúan y se correlacionan entre sí bajo una condición multicausal, se constituyen en fundamentación para el análisis espacial, sustento vital de los patrones territoriales de predicción por establecerse en la ocurrencia de accidentes de tráfico.

El análisis espacial de accidentes de tráfico, como plataforma del análisis geográfico, posee fundamentación en lo físico, lo social y lo económico; le compete el estudio de la distribución de los eventos en el territorio y sus antece- dentes e incidencia en el medio; vincula el análisis de las limitaciones espaciales, temporales y sus atributos. Su enfoque cuantitativo permite el desarrollo de la investigación en temas clave para esta disciplina, tales como las redes con sus nodos y arcos, el tratamiento de los flujos, los movimientos, la interrelación de variables incidentes. Estos tópicos se constituyen en el fondo que desencadena gran parte de la problemática del fenómeno de la accidentalidad.

La accidentalidad es un resultado inexorable de la creciente movilidad. Una visión integral de la planificación del ordenamiento territorial sostenible en Bogotá D.C. debe iniciar con la concordancia entre objetivos de movilidad sostenible y de seguridad vial. Esta ciudad, en sus planes de ordenamiento del territorio y de movilidad, muy poco ha considerado la interacción geográfica de variables en el sistema de transporte, pues la inexistencia de verdaderos nodos de transferencia, la integración intermodal y la deficiencia en la capacidad de un sistema de transporte masivo de pasajeros, seguirá incidiendo en recurrentes períodos de congestión, estado que se traduce en una constante en la presencia de accidentes de tráfico. 


\section{Literatura citada}

Acuña, E. F. (2000). Notas de Análisis Discriminante. Clasificación usando estimación de Densidad por Kernel. Capítulo VIII. ESMA 6835 Clasificación (pp. 62-80). Universidad de Puerto Rico. Mayaguez. Puerto Rico.

Bailey, T. C. \& Gatrell, A. C. (1995). Interactive spatial data analysis. Harlow: Longmans.

Banco de Desarrollo de América Latina. (2011). Desarrollo urbano y movilidad en América Latina. Dirección de Análisis y Programación Sectorial. Recuperado de www.caf. com/publicaciones.

Buzai, G. D. \& Baxendale, C. A. (2006). Análisis socioespacial con sistemas de información geográfica. Buenos Aires: GEPAMA, Lugar Editorial.

Cebollada, I. F. A. \& Miralles, G. C. (2003). Movilidad y transporte. Opciones políticas para la ciudad. España: Laboratorio de Alternativas.

Centre for Advanced Spatial Analysis, UCL. (2003). Review of current practices in recording road traffic incident data: with specific reference to spatial analysis and road policing policy. Working Papers Series, 4-20.

Cerquera, E. F. \& Chías, B. L. (2010). Análisis espacial de los accidentes de tránsito en áreas geográficas urbanas. Caso Bogotá. Proyecto de tesis. Revisión teórica. UPTC-IGAC, Bogotá.

Cerquera, E. F. \& Pérez, B. G. (2007). Accidentalidad urbana y seguridad vial. Facultad de Ingeniería, UPTC-CEDEC. Tunja: UPTC.

Chías, B. L. (1997). Cambios en la estructura del sistema nacional de transportes. En Aguilar A. G. y Rodriguez F. Economía global y proceso urbano en México. Cambios y Tendencias recientes. (pp. 313-360). Cuernavaca, Morelos. UNAM. México.

Chías, B. L. \& Luna, G. L. (1999). El uso de SIG en el análisis de la distribución de accidentes en carreteras: el caso de Tamaulipas. Investigaciones Geográficas, 40, 148-162.

Colombia. Departamento Administrativo Nacional de Estadística DANE. (2010). Estimación y proyección de población nacional, departamental y municipal por sexo, grupos quinquenales de edad y edades simples de 0 a 26 años 1985-2020. Recuperado de http://www.dane.gov.co/index.php?option=com_content\&view $=$ article $\& i d=7$ $5 \&$ Itemid $=72$.

Colombia. Ministerio de Transporte. (2010). Base de datos sobre accidentes en Colombia. Bogotá: Ministerio de Transporte. 
Colombia. Secretaría Distrital de Movilidad SDM. (2011). Movilidad lo hacemos todos. Balance 2008, 2009 Y 2010. Dirección de seguridad vial y comportamiento del tránsito. Bogotá: Alcaldía Mayor de Bogotá.

Colombia. Secretaría Distrital de Planeación SDP. (2009). Destino capital, movilidad sostenible. Subsecretaría de planeación territorial, vías, transporte y servicios públicos. Bogotá: Alcaldía Mayor de Bogotá D.C.

Gioria, B. M. I. (1997). Los medios de transporte organizadores del espacio de la provincia de Santa Fe. Ponencia en las Primeras jornadas regionales de iniciación a la investigación en Geografía. Universidad nacional del Litoral. Santa Fé. Argentina.

Haddon, W. (1980). Advances in the epidemiology of injuries as a basis for public policy. Public Health Reports, 95 (5), 411-421.

Instituto de Seguridad y Educación Vial, ISEV. (2011, julio). Séptimo reporte Mercosur y quinto latinoamericano de siniestralidad vial. Buenos Aires, República Argentina.

Lefebvre, H. (1974). La producción del espacio. Recuperado de http://www.notbored.org/ space.html.

Legendre, P. \& Fortin, M-J. (1989). Spatial pattern and ecological analysis. Vegetation, 80, 107-138.

Litman, T. (2009). Evaluating transportation land use impacts. Considering the impacts, benefits and costs of different land use development patterns. Victoria Transport Policy Institute, 1 (4), 9-16.

Maestre, F. T., Escudero, A. \& Bonet, A. (2008). Introducción al análisis espacial de datos en ecología y ciencias ambientales: Métodos y aplicaciones. Madrid: Dykinson.

Miralles-Guasch, C. (2002). Ciudad y transporte. El binomio imperfecto. Barcelona: Ariel.

Modenés, J. A. (2007). Movilidad espacial: uso temporal del territorio y poblaciones vinculadas. Pamplona. Centre d'Estudis Demogràfics. España.

Moreno, J. A. (1991). Modelización cartográfica de densidades mediante estimadores Kernel. Treballs de la Societat Catalana de Geografia, 30, 155-170

Morera, C. J. (2011). Visión de futuro de Bogotá frente a los problemas de hoy. Recuperado de http://www.monografias.com/trabajos84/vision-futuro-bogota-frente-problemashoy/vision-futuro-bogota-frente-problemas-hoy.shtml.

Newman, P. \& Kenworthy, J. R. (1999). Sustainability and cities: overcoming automobile dependence. New York: Island Press. Retrieved from http://books.google.com.co/ 
books?hl $=$ es\&lr $=\& i d=$ pjatbiavDZYC\&oi $=$ fnd \&pg $=$ PR13\&dq $=$ Sustainability + and + Cities: + Overcoming\&ots $=$ B8OUnQyxyw\&sig $=$ jgN1KzmpmPj2NLbcHBo3 $\mathrm{cZgm} 94 \mathrm{o} \# \mathrm{v}=$ onepage $\& \mathrm{q} \& \mathrm{f}=$ false.

Orfeuil, J. P. (2005). La mobilité nécessaire, quelles réponses en France et à l'étranger? Conferencia impartida en el seminario Mobilités pour l'insertion. Saint Nazaire. Recuperado de http://www.ville-enmouvement.com/plateforme_insertion/telechargement/Conference_JPO.pdf.

O’Sullivan, D. \& Unwin, D. J. (2003). Geographic information analysis. Illustrated edition. Hoboken, NJ: John Wiley and Sons.

Peden, M. et al. (2004). Informe mundial sobre prevención de los traumatismos causados por el tránsito. Resumen. Organización Mundial de la Salud. Ginebra: Banco Mundial.

Potrykowsky, M. \& Taylor, Z. (1984). Geografía del transporte. Barcelona: Ariel.

Rey, C. E. \& Cardozo, D. (2009). La vulnerabilidad en la movilidad urbana. Recuperado de http://hum.unne.edu.ar/publicaciones/instGeo/digitales/vulnerabilidades/archivos/cap11.pdf

Scott, L. M. \& Janikas, M. V. (2008) Spatial Statistics in Arcgis. Encyclopedia of geographic informations. Sage, Thousand Oaks, CA.

Thomson, N. I. (2007, nov.-dic.). Una respuesta latinoamericana a la pesadilla del tránsito. Los buses sobre vías segregadas. Nueva Sociedad (212), 112.

Transportation Research Board, TRB (2000). Urban street concepts. In TRB. Highway Capacity Manual (pp. 10-1-10-47). Washington D.C.: Transportation Research Board.

Transportation Research Board, TRB (2006). Washington D.C. critical issues in transportation. Retrieved from http://onlinepubs.trb.org/onlinepubs/general/CriticalIssues06. pdf.

Ullman, E. L. (1956) The Role of Transportation and the Bases for Interaction, En W. L. Thomas, jr., C. O. Sauer, M. Bates and L. Mumford, 1956, Man's Role in Changing the Face of the Earth, University of Chicago Press, Chicago and London.

Wenglesky, S. (2002). Parcours effectif à l'emploi versus accès potentiel à l'emploi: une mesure des contraintes des actifs dans la métropole parisienne. Colloque annuel de l'ASRDLF, Trois-Rivières, Canada. Recuperado de http://www.uqtr.ca/screg/T_ Wenglenski.pdf. 
Whitelegg, J. (1987). A geography of road traffic accidents. Department of Geography. University of Lancaster. Bailrigg. Lancaster. Transactions of the Institute of British Geographers, New Series, 12 (2), 161-176.

Xie, Z., and Yan, J. (2008). Kernel density estimation of traffic accidents in a network space. Journal of Computer, Environment and Urban Systems, Vol. 32, pp. 396406.

Xumini, S. L. M. (2008). Lógica elemental de la seguridad vial. Recuperado de http:// xa.yimg.com/kq/groups/13240622/1931432794/ name/ Seguridadeinfraestructuras. pdf. 
